\title{
EDUCAÇÃO ESPECÍFICA E DIFERENCIADA: complexos culturais da língua materna Haliti-Paresi
}

SPECIFIC AND DIFFERENTIATED EDUCATION: cultural complexes of the Haliti-Paresi mother tongue
EDUCACIÓN ESPECÍFICA Y DIFERENCIADA: complejos culturales de la lengua materna Haliti-Paresi

\section{Waldinéia Antunes de Alcântara Ferreira \\ Professora da Universidade do Estado de Mato Grosso. Doutora em Educação pela UFRGS. Coordenadora Pedagógica do curso de Pedagogia Intercultural- FAINDI-Unemat-Campus Barra do Bugres-MT. Professora dos programas de pós-graduação em Educação - PPGEdu e Mestrado em Ensino no Contexto Intercultural Indígena - PPGECII. waldineiaferreira@unemat.br. \\ 0000-0001-5949-7590}

\section{Nilce Zonizokemairô}

Mestranda do programa de pós-graduação Strictu Sensu Mestrado em "Ensino em Contexto Intercultural Indígena". Professora da Escola Municipal Indígena Zozoiterô.

\section{0-0001-7657-1027}

Correspondência: Escola indígena Municipal Zozoiterô - Aldeia Rio Verde - CEP 78300-000, Tangará da SerraMT, Brasil.

Recebido em: 12.10 .2020$.

Aceito em: 20.11.2020.

Publicado em: 01.01.2021.

\begin{abstract}
RESUMO:
Este artigo apresenta algumas reflexões relacionadas ao ensino de língua Materna junto ao povo Haliti - Paresi. É resultado de alguns questionamentos proporcionados a partir das aulas no Pós-Graduação Stricto Sensu Mestrado Profissional em "Ensino em Contexto Indígena Intercultural" - UNEMAT, acerca de práticas pedagógicas significativas dentro do contexto da escola específica, diferenciada, intercultural e bilíngue. Aborda o lugar da língua materna na escola e os seus complexos culturais constituídos em histórias, memórias e cultura própria. Localiza a língua materna como língua de instrução na escola, como etnopolítica linguística e como fator fundamental da identidade étnica.
\end{abstract}

PALAVRAS-CHAVES: Língua Materna; Haliti Paresi; Cultura.

\section{Introdução}

Apresentamos, nesta construção textual, uma reflexão feita em dialogicidade, entre autora e coautora, a respeito da língua materna Haliti Paresi como Prática Pedagógica. Trata-se de reflexões empreendidas no Programa de Pós-Graduação Stricto Sensu Mestrado Profissional em "Ensino em Contexto Indígena Intercultural" - UNEMAT. Este diálogo foi fundamentado, principalmente, na vivência da coautora, balizado por outros diálogos efetivados na Aldeia Rio Verde do povo Haliti-Paresi. Portanto, constitui-se num texto construído em aprendizagens e trocas, composições compartilhadas na escuta de uma com a outra.

Trazemos, de início, os Haliti-Paresi, um povo forte que compartilha o território brasileiro com muitos outros grupos étnicos. Um povo originário como tantos outros do Brasil, que tem uma língua materna originária, uma identidade própria, um povo que desafia a continuidade do ser indígena, do ser Haliti-Paresi.

Sabe-se que no início da colonização havia, no Brasil, uma variedade linguística muito grande, mas que a 'colonização', fenômeno que criou na América a racialização e subalternizou os povos originários, foi responsável por diversos genocídios, entre eles, o 
linguístico. Segundo Seki (1999), na atualidade, existe uma estimativa de que ainda são faladas cerca de 180 línguas indígenas no Brasil, no entanto, muito mais eram faladas. Os estudos produzem uma estimativa de que, desde a chegada dos Portugueses, é possível que se tenham perdido pelo menos 1.000 línguas. As línguas faladas estão "distribuídas em cinco grandes grupos: Tronco Tupi, Tronco Macro-Jê, Família Karib, Família Aruak, Família Pano, havendo ainda nove outras famílias menores e dez Isolados linguísticos" (p. 259).

Ainda que se apresente em pesquisa essa estimativa, não se pode esquecer de que essas línguas indígenas continuam sendo ameaçadas, sofrendo impactos decorrentes do contato com a língua portuguesa, ou seja, a língua majoritária do país

No Brasil atual, os falantes de línguas Aruak se encontram distribuídos desde a divisa com as Guianas até o estado de São Paulo. No Estado de Mato Grosso seus parentes linguísticos são os Enawene Nawe, que habitam a região entre o rio Juruena e a Serra do Norte; os Waurá, os Mehinako e os Yawalapiti do Alto Xingu e os Terena da Terra Indígena Gleba Iriri. (Haliti-Paresi, 2019)

Assim, o povo Haliti-Paresi é falante da família linguística Aruak e estão no Estado de Mato Grosso, aldeados em nove Terras Indígenas: Paresi, Utiariti, Rio Formoso, Juininha, Estivadinho e Figueiras já homologadas e demarcadas; as Terras Indígenas Uirapuru, Ponte Pedra e Estação Parecis que estão em processo de demarcação. Essas terras ocupam os espaços geográficos dos municípios de Tangará da Serra, Sapezal, Campo Novo do Parecis, Conquista do Oeste, Barra do Bugres, Campos de Júlio, Nova Lacerda, Diamantino e Nova Marilândia. Atualmente, a população atual está contabilizada em 2.186 habitantes.

A Terra Indígena Paresi tem uma extensão de 563.586 hectares, está localizada no município de Tangará da Serra-MT, ressaltando-se que 52 por cento do município é terra indígena. A aldeia Rio Verde que é o lócus de inserção da escola em discussão, pertence ao município de Tangará da Serra-MT, onde moram 21 famílias, com uma população de 65 pessoas.

A língua materna é muito importante para um povo, é a essência da interação e comunicação entre os povos, é o elo e fortalecimento cultural de uma determinada sociedade, pois tem uma importância muito grande nas manifestações socioculturais, por isso, simboliza a identidade de um povo.

Em se tratando do povo Haliti Paresi, há uma preocupação por parte dos anciões e lideranças tradicionais com a língua materna na atualidade. Essa preocupação diz respeito à preservação, valorização e fortalecimento da língua mãe que corre, como muitas outras 
línguas originárias, o risco de desaparecer. Essa hipótese de ameaça de desaparecimento é resultado de diversos aspectos que, ao longo do tempo, vem causando impactos e transformações socioculturais na sociedade Haliti Paresi. O desaparecimento da língua materna e, mesmo tempo as ameaças, de alguma forma, impactam o povo, inclusive, na questão da religiosidade e espiritualidade que tem uma ligação muito forte com a língua materna Haliti Paresi. Tais elementos têm "na língua materna a expressão de sua identidade étnica (afirmação dos próprios Paresi)" e (PAES, 2002, p.52). Ainda que tenham intenso contato com a sociedade não indígena, a manutenção da língua materna é a própria manutenção do ser Paresi.

A língua materna é fundamental para a sobrevivência da comunidade Haliti Paresi como um povo indígena, é a defesa do povo, considerando que é também um conhecimento tradicional, explica Nazokemai (2018). É um dos elementos mais importante da identidade cultural de um povo indígena, um saber que vem desde os ancestrais. Pela língua materna, o povo Haliti Paresi vem fortalecendo e valorizando a sua essência e cultura espiritual, aprendendo a valorizar os conhecimentos milenares do seu povo. Continuam repassando esses saberes pela língua materna para as novas gerações, desta forma, faz-se com que nunca se esqueçam da sua cultura e dos valores do povo indígena Haliti Paresi.

Dentro desse contexto, de significação da língua materna, é possível que se questione: Todos os Haliti-Paresi, dos territórios deste povo originário, são falantes da língua originária? Sobre isso, pode-se dizer que a história calou muitos Haliti, resultando numa realidade sociolinguística que difere entre aldeias e dentro dos subgrupos.

O Plano de Gestão Haliti Paresi (2019) aponta que nos dias atuais, há representantes dos subgrupos Kozarene, Waymare, Katxiniti, Warere, Kahete enomaniyere, este último, não registrado na bibliografia histórica sobre os Haliti".

No entanto, de acordo com Nilce Zonizokemairô, há dois subgrupos Haliti Paresi, Kozarene e Waimare que têm grande número de representantes e, no que se refere à situação sociolinguística, o subgrupo Kozarene, na sua grande maioria, pelo menos $90 \%$, são falantes da língua materna. A crianças aprendem a falar na língua desde quando começam a entender e aprender alguma coisa da cultura, da vida do Haliti-Paresi. Os pais e a família têm a obrigação de ensinar a língua materna para os filhos.

Mesmo que grande parte dos Kozarene sejam falantes, há preocupações, pois, toda língua originária está em constante ameaça. Assim, uma das preocupações na atualidade, na aldeia Rio Verde, com o subgrupo Kozarene, diz respeito à influência dos não indígenas (missão evangélica), que podem, com o tempo, interferir na língua materna das futuras gerações. 
No subgrupo Waimare há poucas pessoas falantes da língua originária, as crianças, adolescentes, jovens e adultos só falam na língua portuguesa, no seu dia a dia, e tudo isso vem acontecendo devido à miscigenação entre as pessoas. Essas situações de contato com imuti (não indígena) têm impactado na questão da língua materna, pois quem sabe falar não consegue mais repassar esse conhecimento para a geração mais nova. Muitas vezes, alguns jovens ficam com vergonha de aprender e também de falar na sua própria língua materna. Por outro lado, os pais e a família não conseguem mais ensinar aos seus filhos, achando que a língua portuguesa é mais importante que a originária, mesmo que essa seja a língua usada na manifestação do sagrado.

Esses motivos justificam a necessidade da comunidade indígena do povo HalitiParesi assumir uma etnoeducação e uma educação diferenciada no sentido da inclusão da língua materna como etnopolítica ou como uma política etnoeducativa. Nesse sentido, é "etnopolítica, porque diz do próprio povo, em estado de reflexão e de memória" (FERREIRA, 2020, p.69) e, ainda, porque assume o princípio da decolonialidade. Também se caracteriza como etnoeducação, porque compõe uma educação ancestral e transgeracional, portanto, política etnoeducativa.

Nessa perspectiva, como política linguística e decolonial, os Haliti da aldeia Rio Verde, que fica na Terra Indígena Paresi, em Tangará da Serra-MT, têm assumido a construção de uma escola diferenciada, onde os saberes e a cultura, a iniciar pelo próprio povo, sejam valorizados e incluídos (quando possível) no currículo escolar. Que seja uma educação escolarizada, conforme a luta dos povos originários e preconização legal, uma educação escolar comunitária, especifica, diferenciada, bilíngue ou multilíngue. É preciso que seja uma escolarização constituída dentro de uma dinâmica em que a escola é um instrumento, uma ambiência institucional que significa abordagens culturais e sociais, sendo um processo intra e intercultural que fortaleça o que lhes é próprio, e também possibilita acessos a outros conhecimentos, denominados de 'universais'.

Nesse sentido, há um esforço na construção de uma educação escolarizada que contemple a pedagogia do próprio povo Haliti-Paresi, pois, compreende-se que a educação escolar indígena tem o papel fundamental de estar significando, repassando, fortalecendo e valorizando os saberes e conhecimentos tradicionais do povo Haliti Paresi. É preciso uma escola que assuma o reconhecimento da diversidade, da própria cultura, e da língua enquanto veículo identitário, com vistas a manutenção desta, apropriando-a no espaço escolarizado como disciplina, conteúdo, grafação, alfabetização e letramento indígena. Uma escola que na atualidade experiencia pedagogicamente a constituição efetiva de uma educação escolarizada específica e diferenciada, uma construção que se dá pautada na memória, nas dores encarnadas do povo a respeito das histórias 
aprendidas com os mais velhos sobre os primeiros contatos com o imutie com o processo de ensino-aprendizagem dominante, no silenciamento e anulamento da identidade e da língua materna, mas, também, da aprendizagem da escrita em Aruak. São complexos que se emaranham em sentidos e sentimentos, conflitos e manutenção da língua originária, porque própria, ancestral e identitária.

Portanto, construir uma educação escolarizada outra, específica, diferenciada, intercultural e bilíngue protagonizada pelo próprio povo Haliti-Paresi perpassa por lutas do movimento indígena, na busca da garantia da alteridade e da apropriação do contexto escolar, sob a ótica da etnoeducação produzida em interculturalidade. Uma interculturalidade aprendida e crítica porque se esperam transformações no contexto das sociedades indígenas e não indígena, pois a escola é um campo de fronteira étnica, ainda que estando dentro das aldeias.

Desta forma, a escola indígena é o movimento da apropriação intra e intercultural, onde pela escola se utiliza a 'caneta', objeto que produz escrita que beneficia - no sentido do direito - ou não os povos originários. A caneta representa a escrita em muitos aspectos, que se encontram no campo da justiça e acesso a direitos aos povos originários que, muitas vezes, foram negados. Também representa a produção de histórias pelo olhar do colonizador, mas, também, é preciso reconhecer que por ela produziram análises e constructos decoloniais. Os povos originários a querem também sob vossos cuidados com a finalidade de escreverem a própria história para acessar justiça e direitos. Essa vontade etnopolítica fica evidenciada nas palavras do professor Lino Zokenazokae quando dia que "antigamente nós usávamos o arco e a flecha. Atualmente a gente trocou o arco e a flecha e defendemos nossos direitos na ponta da caneta" (Haliti - Paresi, 2019, p. 140.). Temos aí uma metáfora da dominação do objeto, dos elementos que constituem o mundo não indígena. Assim a troca, não significa o deixar sua cultura, mas em movimento, assumir a postura de mármore e murta, conforme Viveiro de Castro (2002), quando escreve sobre a inconstância da alma selvagem. Ou seja, a troca existe quando for preciso fazê-la, mas, posteriormente, retomam-se os objetos próprios da cultura. Assim, também o é a escola, lugar de movimento e de diferentes trocas, a escola específica e diferenciada.

\section{Emaranhados históricos da narrativa sobre a educação específica e diferenciada no contexto Haliti Paresi}

A construção da educação escolar indígena, como buscada pelos povos originários e, neste caso, pelo povo Haliti Paresi, resulta de um complexo de memórias, vivências encarnadas em aprendizagens dolorosas e emancipatórias que fazem parte de um 
continuum pedagógico que se dá, inclusive, na atualidade revestido do protagonismo cultural dos Haliti-Paresi. Assim, a reflexão desta parte textual tem a finalidade de produzir uma aproximação, ainda que descritiva, com um período histórico da própria educação brasileira, da instituição escola e, alguns poucos apontamentos sobre a escolarização do povo Haliti Paresi, principalmente, no tocante a língua materna.

Sabe-se na história da educação brasileira, que a finalidade da instituição escola, para os povos indígenas, teve como objetivo primeiro, ser veículo integrador das populações indígenas com a sociedade não indígena. Assim, as línguas originárias eram obstáculos nesse processo integrador e a escola, historicamente, assumiu a responsabilidade de ensinar a língua portuguesa. Então, era projeto do governo português ampliar o uso da língua portuguesa, fortalecer o Estado, inserir os índios na sociedade colonial. E a escola foi um desses instrumentos dentro desta panorâmica, inicialmente, junto à Companhia de Jesus, que desenvolvia o trabalho de ensinar a língua portuguesa, a catequese e a conversão das populações indígenas, posteriormente, essa congregação é expulsa do território colonial brasileiro.

Os jesuítas são afastados, porém, há um continuum colonizador, organizações políticas de subalternidade e de assimilação em processo, intensificado com contatos com o não indígena, para os Haliti com os Imuti.

Conforme Paes (2002), a história da escolarização com o povo Haliti Paresi ocorre por volta de 1920, época em que Marechal Rondon coordenava e acompanhava as instalações das linhas telegráficas e, também, período da fundação da escola-internato de Utiariti. Tratava-se de uma escola de sistema rígido, militaresco, positivista, com proposta de produzir uma formação que atendesse a integração dos indígenas à sociedade nacional, principalmente, na condição de cidadãos para a defesa das fronteiras brasileiras, bem como, para atender a sociedade como trabalhadores, portanto, o grande objetivo era a integração na sociedade nacional na condição de trabalhadores (Pivetta, 1999).

O internato-escola do Utiariti, mais tarde, passou a ser gerido pela missão Jesuítica e se constituiu sob a égide de modelos colonialistas; um que atendia aos objetivos do SPI - Serviço de Proteção ao Índio, ou seja, objetivos integracionistas e o outro, a partir da gestão dos Jesuítas, entre 1935-1970, fazendo a "[...] transformação de pagãos em cidadãos cristianizados e trabalhadores nacionais" (PIVETTA, 1999, p. 88).

A escola-internato introduziu a língua portuguesa e teve como principal função ensinar os alunos indígenas a falar e a ler e escrever em português. Depois, com a criação da FUNAl, em 1967, assumindo a educação escolarizada nas aldeias, ela cria uma política de grafação da língua originária. Para isso, o país faz parceria com a agência missionária 
evangélica Summer Institute of Linguistics (SIL) que teve o objetivo de elaborar materiais de alfabetização para diversos povos indígenas do país. "Pela portaria da Funai de 1972, a regra a ser seguida na criação dos alfabetos para as escolas seria: "para cada fonema, um único símbolo" (BARROS, 2004, p.) Assim, se dá a oficialização do programa de educação do SIL no Brasil. Entre os muitos materiais produzidos, se encontra um dicionário da língua Haliti-português do povo Haliti-Paresi e a bíblia escrita na língua materna.

É importante destacar que, em 1973, criou-se o Estatuto do Índio, a Lei n 6001/73 e, neste, aparece a normatização a respeito da alfabetização dos indígenas. Conforme o Estatuto em seu Art. 49, "a alfabetização dos índios far-se-á na língua do grupo a que pertençam, e em português, salvaguardado o uso da primeira" (BRASIL, 1973).

E mais recentemente, a Constituição de 1988 traz uma abordagem não apenas da língua materna, mas também a proteção da cultura, dos modos próprios de fazer, aprender, viver, que se referem aos saberes indígenas:

\begin{abstract}
Art. $210 \S 2^{\circ}$. O ensino fundamental regular será ministrado em língua portuguesa, assegurada as comunidades indígenas também a utilização de suas línguas maternas e processo próprio de aprendizagem.

Art.215: O Estado garantirá a todos o pleno exercício dos direitos culturais e acesso às fontes da cultura nacional, e apoiará e incentivará a valorização e a difusão das manifestações culturais.

$\S 1^{\circ}$. O Estado protegerá as manifestações das culturas populares, indígenas e afro-brasileira, e das de outros grupos participantes do processo civilizatório nacional.

Art. 231 São reconhecidos aos índios sua organização social, costumes, línguas, crenças e tradições, e os direitos originários sobre as terras que tradicionalmente ocupam, competindo à União demarca-las, proteger e fazer respeitar todos os seus bens.
\end{abstract}

Há com a Constituição Federal de 88, resultado de muitas lutas, inclusive, dos povos originários, seguridade legal quanto ao reconhecimento da diversidade étnica, especificidade nas constituições diferenciadas, próprias de cada povo. Mas, ainda no final dos anos de 1980, é a Prefeitura Municipal de Tangará da Serra que faz a gestão escolar das escolas indígenas, implementando as mesmas orientações e práticas pedagógicas das demais escolas de ensino fundamental (PAES, 2002). Ou seja, as formas próprias de aprendizagem, a especificidade, a diferença e mesmo a língua materna parece muito pouco ou quase nada se faz presente nesta ambiência educativa.

Grando (2000) aponta que a educação escolarizada, em áreas indígenas no Brasil, é dividida em fases. Assim, em completude com a discussão anterior, apresentamos que a primeira fase é a educação religiosa que buscou a conversão do indígena (período colonial); a segunda é marcada com a criação do SPI, a partir de 1910, como já 
mencionado, positivista, com uma estrutura rígida; depois esta é substituída pela Fundação Nacional do Índio-FUNAI. É também nesta segunda fase que aparece o Summer Institute of Linguistics (SIL). A terceira fase é iniciada na década de 70, período em que há organização do movimento indígena e surgimento de práticas indigenistas com a participação de indigenistas e de organizações não governamentais, período das lutas por territórios.

Conforme Grando (2000), há o desenvolvimento de um trabalho educacional articulado, onde a luta se dá na garantia de acessos a direito ao território, saúde e cultura indígena. Compõem essa luta, junto aos indígenas do país,

[...]o Conselho Indigenista Missionário (CIMI), a Operação Anchieta $(\mathrm{OPAN})$, a Comissão Prolndio (CPI), o Centro Ecumênico de Documentação e Informação (CEDI), entre outras. Nesta fase, o Movimento Indígena junta-se aos demais movimentos sociais no país. Esse período da história foi marcado pela luta dos segmentos sociais oprimidos pelo sistema vigente (GRANDO, 2000, p.73).

Esse movimento surge na década de 80, não apenas no Brasil, mas também, em outros países com o reconhecimento de uma modalidade específica de educação. No Brasil, com uma educação escolar indígena específica, diferenciada, intercultural e bilíngue/monolíngue. Conforme Monte (1997), no Brasil, essa especificidade é denominada de educação intercultural bilíngue e nos demais países da América Latina denomina-se etnoeducação.

Houve, portanto, um movimento nacional, na década de 1980, estendendo-se para as décadas posteriores, na busca de implementação de uma educação escolar indígena que atendesse às especificidades étnicas, que realmente reconhecesse a diversidade e a alteridade dos povos indígenas. É importante lembrar que foi apenas em 1991, que a educação escolar nas aldeias passou a ser responsabilidade do Ministério da Educação.

Nesse constructo, ou nesse emaranhado complexo constituído, e com a perspectiva de se ter uma escola que desse conta da construção de pedagogias indígenas, necessário se fez, também, lutar por formação específica para educadores indígenas. E é nesse contexto que os Haliti-Paresi, no Estado de Mato Grosso, participaram, a partir de 1996, do Projeto Tucum -Programa de Formação de Professores Índios para o Magistério Intercultural, encerrado no ano 2000. O projeto fundamentou-se na valorização da cultura, terra e da língua (Paes, 2002).

O povo Haliti-Paresi participou de outras formações interculturais, como o projeto Hayo, Terceiro Grau Indígena da Universidade do Estado de Mato Grosso, atualmente, Faculdade Indígena Intercultural que tem a função, a partir de cursos específicos, 
promover a formação de professores indígenas do Estado $E$, mais recentemente, do programa de Pós-Graduação Stricto Sensu Mestrado Profissional em "Ensino em Contexto Indígena Intercultural" - UNEMAT. Todas essas formações são resultadas das lutas indígenas.

De acordo com os Haliti Paresi, a escola específica e diferenciada é sonhada pelo povo, pensa-se em uma escola intercultural proposta pela Constituição Federal de 1988, com respeito ao povo, a cultura, aos costumes e a língua materna.

Nesses termos, a escola indígena precisa ser de fato construída em processo, de maneira decolonial, uma ação que é cotidiana e objetivada. Precisa ser olhada como uma política pública diferenciada e especifica, uma política em que os professores/as indígenas sejam valorizados, pois o que acontece é que existe uma precarização do trabalho do docente indígena. É preciso que a lei efetive na realidade a produção de material didático que atenda aos povos originários em suas especificidades. A realidade do povo Haliti Paresi é que não há, por parte da esfera governamental, apoio e mesmo produções desses materiais. Mas, há uma prática constante entre os(as) educadores(as) que é a pesquisa intracultural e produção de materiais escritos que auxiliam a etnopolítica e a política linguística. É uma experienciação pedagógica em que os Haliti-Paresi assumem a autodidatização da escrita e do ensino da língua materna dentro das possibilidades criadas, porém, ainda distante da sonhada, principalmente, no que se refere à publicação do material didático próprio, específico e diferenciado (impresso).

\section{Língua materna na escola: complexos culturais encarnados}

O ensino da língua materna nas escolas indígenas tem como objetivo a valorização e o fortalecimento da língua originária de um determinado povo. Assim também o é para o povo Haliti Paresi.

A língua materna serve para comunicar, expressar, registrar, reconhecer e refletir sobre a diferença de 'dialeto' entre os subgrupos, segundo os Haliti Paresi. Compreendese, nesta perspectiva, o dialeto como uma variação linguística entre os subgrupos. Essas variações existem em decorrência do subgrupo, ou seja, é uma característica cultural do contexto da comunicação. Essa variação é assumida pelos subgrupos e a língua materna trabalhada na escola respeita essa especificidade.

A discussão que se segue apresenta a organização de uma prática pedagógica de educação intra e intercultural, ou seja, de uma etnoeducação na Escola Municipal Indígena Zozoiterô que consideramos, a partir de nossas avaliações e constructos didáticopedagógicos, especifica, diferenciada e bilíngue. É um lócus de educação escolarizada pensada com base na realidade do povo indígena Haliti Paresi, é também intercultural 
porque abarca outras culturas e se relaciona com os conhecimentos e diálogo entre a cultura indígena e não indígena, desta forma, muitas vezes, enfrentando o desafio das relações assimétricas de poder, por parte do lado ocidental.

É importante ressaltar que, de acordo com Paes (2002), desde o ano de 1999, o grupo de professores Haliti-Paresi adotaram uma postura de serem os protagonistas da condução pedagógica na escola, inclusive, inserindo no currículo escolar, elementos da cultura, assim como, por falta de terem materiais didáticos específicos, adaptar os livros do Programa Nacional do Livro Didático para a realidade do povo Haliti-Paresi.

Há na organização curricular a disciplina de língua materna e esta se faz presente em todos os níveis de educação e serve para os estudos relacionados à escrita da língua, uma vez que na Aldeia Rio Verde (lugar de onde falamos) crianças, jovens e velhos são falantes.

Os(as) professores(as) Haliti-Paresi concordam que a disciplina de Língua Materna é um dos lugares do currículo que pode ser feita a transmissão da mitologia dos ancestrais, dos conhecimentos tradicionais do povo, das ciências socioculturais e ambientais. Assim, a disciplina de Língua Materna trabalha a organização social do povo, os valores culturais, étnicos e linguísticos e tudo aquilo que faz parte da vida cotidiana das crianças e jovens da aldeia, como a solidariedade, a justiça, a união, a política, os rituais tradicionais, enfim, trabalha-se a cultura tradicional Haliti Paresi. Assim, o conteúdo da disciplina está composto fundamentalmente pela cosmologia e cosmovisão do povo Haliti-Paresi.

Ainda é objetivo da disciplina e mesmo da comunidade que a criança e o jovens indígena Haliti Paresi sejam capazes de compreender que o uso da língua materna é um meio de comunicação e de manifestação dos pensamentos e sentimentos das pessoas e do povo. É preciso, ainda, reconhecer e valorizar a diversidade linguística que existe entre os subgrupos Haliti Paresi e compreender como e porque surgiu a escrita na língua materna na sociedade Haliti Paresi.

Considerando a abrangência e a complexidade filosófica do pensamento das finalidades da disciplina Língua Materna, é possível expressar que as significações de não apenas oralizar, mas grafar o Aruak, é uma decisão etnopolítica com uma prática que se insere na educação intercultural e mesmo intracultural. Ao nos referirmos a esta disciplina, inferimos pelos sentimentos e narrativas, bem como, pelos diálogos dentro da própria comunidade com educadores, lideranças e anciãos, mostrando que o objetivo do ensino da língua materna é uma forma de defesa, considerando que a língua também é um conhecimento tradicional do povo. Por ela se pode acessar, não apenas o lócus indígena, mas a comunicação, os rituais tradicionais, a etnopolítica, a política social dos imuti, a 
justiça social e os direitos humanos. Sabemos que a língua materna para os imuti referencia a identidade do Haliti Paresi, tornando-se elemento de grande importância na luta dos povos indígenas.

\begin{abstract}
O professor Ângelo Kezomae, diz que o ensino de língua materna na escola é primordial para o fortalecimento da cultura de modo geral, e também a importância de registrar através da escrita tudo que é contado na oralidade pelos anciões. Na opinião de Willian Mars Cristiano Nazokemai, a língua materna é a essência da comunicação tradicional do povo Haliti Paresi, no aspecto sociocultural é um dos códigos essenciais para as praticais culturais, principalmente, nos rituais, a importância que tem de aprender a língua materna dentro da escola é para fortalecer e valorizar a língua e os conhecimentos tradicionais, também para aprender a ortografia da língua materna através da escrita, é por isso que é importante o ensino da língua materna dentro das escolas indígenas para a aprendizagem das crianças. (KEZONAZOKERO, 2020, p.)
\end{abstract}

Assim, reafirmamos que a disciplina em sua complexidade e a aprendizagem da escrita em Aruak, é um movimento etnopolítico linguístico, que se dá em dois movimentos intracultural e intercultural crítico.

O primeiro, intracultural movimenta-se no sentido da cosmogonia Haliti-Paresi, com objetivos voltados ao povo, no ensino da oralidade, das tradições, dos significados dos rituais, fundamentados na ancestralidade que respondem ao próprio povo, a encarnação do ser Haliti-Paresi.

De acordo com Martins (2018), a intraculturalidade é um processo em que há por parte dos indígenas um reconhecimento e um conhecer-se etnicamente consubstanciados pelas memórias e histórias ancestrais. É também fundamento para a busca de lutas, resistência; é a conjugação de dois fatores, um é interno e diz respeito a tradições próprias e o outro é externo, mediado pela característica da sociedade indígena brasileira e latino-americana.

Assim, trata-se de um fenômeno em que a tomada de consciência histórica é feita no reconhecimento identitário, dentro das relações sociais e históricas vivenciadas pelo respectivo povo. Marín (2014) explica que a tomada de consciência é primordial para que os povos possam compreender a vivência presentificada, a sua cotidianidade e os conflitos passados e atuais, e por ela - tomada de consciência histórica - é possível prever uma etnopolítica futura. Ou seja, abre-se a possibilidade da realização de uma análise em que se reconhece a si mesmo etnicamente para construir a figura do outro, com uso da dialogicidade e implementação da interculturalidade.

Uma interculturalidade que seja crítica, que se orienta para uma construção democrática, plural e humana das sociedades, articulando políticas de igualdade com 
políticas de identidade (CANDAU, 2008). Nessa perspectiva a língua materna assume o lugar do reconhecimento étnico, tanto para os povos indígenas quanto para a sociedade nacional.

No sentido intracultural, questionamos: o que é preciso para ensinar a língua materna na comunidade do povo Haliti-Paresi? Assim, é de consenso que, primeiramente, seja um(a) Haliti-Paresi.

Ensinar a língua materna exige que o(a) professor(a) indígena tenha o domínio dos saberes da cultura do seu povo, pois o é planejado para ensinar os(as) alunos(as) vem das histórias, crenças e rituais. Desta forma, os eventos culturais que acontecem na aldeia já são previamente incluídos no calendário da escola. Um exemplo disso é quando acontece a festa da menina moça na aldeia e todos participam, o(a) professor(a) escolhe o tema e elabora o seu plano de aula, conforme os acontecimentos. Realizam-se as atividades como produção de texto, leitura, formação de frases e palavras, ensinam-se, também, os significados do ritual que são feitos na vivência, na escola, e em comunhão com toda a comunidade.

Reafirmamos que com a disciplina, mas, fundamentalmente, por meio da língua materna é que o povo indígena Haliti Paresi fortalece a própria língua e a cultura espiritual. Ela está na escola enquanto conteúdo, disciplina, mas ela é a própria espiritualidade Haliti-Paresi, em cânticos, nos rituais, nas benzeções, etc. Nessas vivências, os jovens e crianças Haliti Paresi aprendem a valorizar os conhecimentos milenares do seu povo e se preparam para torná-los a viver, de maneira que passam para as outras gerações, fazendo com que nunca se esqueçam a cultura e os valores Haliti Paresi.

Como já dissemos anteriormente, a língua materna é disciplina e é trabalhada em todas as etapas de escolarização das crianças e jovens Haliti-Paresi. Assim, consideramos a Escola Municipal Indígena Zozoiterô específica, diferenciada e intercultural, pois foi e é pensada e repensada com base na realidade do povo indígena Haliti-Paresi. É intercultural, de acordo com o entendimento dos professores(as) Haliti-Paresi, pois dialoga, negocia e trabalha uma abrangência do próprio contexto, como também do contexto ocidentalizado, universal.

É fundamental para a Escola Municipal Indígena Zozoiterô, a alfabetização das crianças, adolescentes e jovens na língua materna do povo, pois, além de serem falantes, precisam aprender a ler e a escrever na língua originária, conhecer e aprender a ortografia e gramática Haliti Paresi, para que possam produzir textos na língua Haliti Paresi.

A língua materna Haliti Paresi tem um grande significado para o povo, ela faz parte da festa tradicional, oferenda, flauta sagrada, flecha sagrada, benzeção, história, txihyali, dança, reza, entre outras coisas que fazem parte da cultura. É por meio da língua materna 
que os pajés, idosos e anciões fazem o pedido em reza, benzeção e oferenda e chamados nas ocasiões especiais e nos momentos ruins do nosso cotidiano, porque é através dela que pedimos nossa proteção para nosso grande protetor Enore (Deus).

A alfabetização acontece na língua Haliti, todas as explicações são feitas na língua materna. Os professores (as) ensinam os alunos com o contexto do próprio povo. Apresenta-se a forma de viver dos Haliti-Paresi e as crianças aprendem as palavras no idioma próprio. Por exemplo, quando se fala de animais como kolota, zotyare, hozore, conta-se história, fala-se dos significados deles na cultura, utiliza-se de ilustração que pode ser feita pelas crianças. Ensina-se a escrever na língua materna, porque falar as crianças já sabem. A alfabetização na língua materna, assim como, o ensino da língua materna acontece como já foi explicado, com a seleção de temáticas da cultura do povo Haliti-Paresi. Conforme Brasil (1999) a língua materna é a língua de instrução oral do currículo, utilizada em sala de aula para trabalhar diferentes conceitos. Ela é a mediatizadora das compreensões da cosmovisão indígena e também da aprendizagem do mundo não indígena.

São seleções do contexto cultural do próprio povo Haliti-Paresi, com as crianças pequenas trabalham-se as palavras, ensinando-as a escrever. Nos anos iniciais, usa-se mais a língua materna e nas séries finais mais a língua portuguesa. As crianças começam a estudar e serem alfabetizadas com 6 anos. A língua materna é a mais falada nas aulas, os(as) professores(as) usam a língua materna para explicar os conteúdos que ministramos durante as aulas, ou seja, ela é a língua de instrução. Os conteúdos abrangem o complexo cultural e também alguns conhecimentos universais. Temos nosso próprio alfabeto, que é diferente do português, como por exemplo: com as vogais: A : atyali (frutas); E: etseti (ovo); I: iyiti (flor); O: olo (dinheiro) e U: uwi (cobra).

O exemplo dado demonstra que por mais que existam seleções de temáticas que fazem parte do complexo cultural do povo Haliti-Paresi, há também uma persistência e influência da metodologia alfabética associada à palavração e aos significados dessas palavras. Uma sistemática influenciada pela educação brasileira e no início da escola no país. Evidencia-se, nesta experienciação, uma construção pedagógica mediatizada por elementos da didática intersticionada por campos sistêmicos de educação vivenciados no campo histórico, porém, também ressignificados na condução metodológica, ao se fazer aberta e dimensionada pela etnopolítica.

Assim, a alfabetização inicial e também a continuidade da alfabetização, nos anos finais do Ensino Fundamental, ocorrem na língua materna e vão se aprofundando, também, no português, porém, todo o apoio para tais aprendizagens se fundamentam na fala originária, de forma que esta mediatiza toda a aprendizagem e a escrita das 
palavras. Todas as disciplinas são ensinadas nas duas línguas, língua materna e língua portuguesa.

A escola, ao introduzir tanto a língua materna quanto a portuguesa no currículo da escola indígena, "pode ajudar no processo de desaparecimento de uma língua indígena, e também pode, por outro lado, ser mais um elemento que incentiva e favorece a sua manutenção ou revitalização. (BRASIL, p. 119). De outra forma, grafá-la pode significar invadir na escola o "domínio da língua majoritária, conquistando um de seus mais importantes territórios" (p. 119).

\section{Considerações finais}

As reflexões sobre o ensino da língua materna Haliti Paresi e seus significados compõem ainda aprendizagens que se inserem na elaboração/movimento de uma pedagogia indígena Haliti-Paresi. Os apontamentos feitos estão consubstanciados nas vivências, nas negociações, nas memórias e na encarnação de se fazer uma escola específica e diferenciada com aprendizagem própria.

Apontamos, ainda, nas reflexões que reconhecemos as mudanças históricas e significativas no que se refere ao fortalecimento da língua materna, e afirmamos que a língua está diretamente relacionada à valorização da cultura tradicional entre os mais jovens e os estudantes. Sabemos das ameaças em curso, em se tratando da língua materna, mas retomamos que ela é do próprio fortalecimento da cultura, porque é através da língua materna que são realizados os rituais, os cerimoniais, as rezas, os cânticos, os cantos, as benzeções, a pajelança, a festa da menina moça, de batizado, as oferendas, a roça, a caça, a pesca, enfim, tudo que envolve a parte cultural e espiritual, a cosmovisão do povo Haliti-Paresi. Essa perspectiva demonstra que a língua do sentido cultural assume o lugar pedagógico, assim, quando a língua assume "o lugar pedagógico, assume também o lugar político e de memória ancestral que a define como parte identitária do corpus cultural de determinado povo." (Ferreira, Cruz e Zitkoski, 2019, p. 43).

Compreendemos que a escola tem um papel fundamental nesse processo, juntamente com a comunidade escolar. Espera-se que realmente tenhamos a produção de materiais didáticos, pois, o povo Haliti-Paresi tem muitos registros de organização de trabalhos pedagógicos de conteúdos da língua materna. Como destaca Brasil (1999), a organização pedagógica dos povos indígenas tem pautado na preparação do estudo, na pesquisa e na produção de registros que nos auxiliam nas práticas pedagógicas. Existe a intenção de publicações, por acreditarmos que é importante para as futuras gerações Haliti-Paresi, porque a língua materna é a essência e identidade de um povo. 


\section{Obevisto}

Reconhecemos que a participação de professores(as) indígenas em formações docentes interculturais aumentou a perspectiva de valorizar e fortalecer a educação específica, diferenciada e bilíngue, a partir da escola. Porém, também sabemos que essas formações são resultados da luta empreendida por muitos povos originários do país. Ainda dentro de todas essas considerações, queremos evidenciar que dialogar sobre o ensino de língua originária na escola é sempre um desafio, e muito mais ainda, falar sobre alfabetização indígena, pois não se trata de uma única alfabetização, são alfabetizações que se inserem nos letramentos indígenas, porque são específicos e diferenciados.

Por ora, finalizamos está reflexão, com muitos questionamentos, e compreendemos que necessário se faz definições de políticas públicas e de estudos/pesquisas que se remetam mais fortemente aos processos de alfabetização dentro das comunidades indígenas, com o intuito de, em observância e vivência, registrar e produzir novas experiências.

Por fim, citamos Freire com a pedagogia do oprimido (2011) e da autonomia (1996), reconhecendo que as pedagogias indígenas se pretendem autônomas. E rememoramos que é preciso que se reconheça que todos temos direito ao território, à educação específica, diferenciada, intercultural, bilíngue ou multilíngue, que temos direito a nossa língua originária. Que pelas pedagogias indígenas e pela manutenção da língua HalitiParesi possamos produzir uma educação emancipadora com tomada de consciência histórica e em interculturalidade crítica.

\section{Referências}

BRASIL. Estatuto do Índio. Lei nº 6001 de 19 de dezembro de 1973

BRASIL. Constituição da República federativa do Brasil, 1988.

BRASIL. Referencial Curricular Nacional para a Educação Indígena. Brasília: MEC/SEF, 1999.

CANDAU, Vera Maria. Direitos humanos, educação e interculturalidade: as tensões entre igualdade e diferença. Revista Brasileira de Educação, v. 13 n. 37 jan./abr. 2008.

FERREIRA, Waldinéia Antunes de Alcântara. Produções de sentidos: movimentos decoloniais na vivência do Programa Institucionalizado de Iniciação à Docência. RELVA, Juara/MT/Brasil, v. 7, n. 2, p. 63-73, jul./dez. 2020.

Ferreira, W. A. de A.; Cruz, M. C. da \& Zitkoski, J. J., Mulheres Kawaiwete e Nambikwara: Guardiãs da língua materna. In Ferreira, W. A. de A.; et al. (Org). Mulheres e Identidades: Epistemologias do Sul - Mulheres, Territórios e Identidades, vol 3. Curitiba: CRV, 2019, p.37-45.

FREIRE, Paulo. Pedagogia do oprimido. 50. ed. São Paulo: Paz e Terra, 2011.

FREIRE, Paulo. Pedagogia da Autonomia: Saberes necessários à prática educativa. São Paulo: Paz e Terra, 1996.

GRANDO, Beleni Salete Grando. Movimentos Indígenas do Brasil: a cultura autoritária e preconceituosa e a Educação Física. Motrivivência: Ano XI, 14, Maio/2000. Disponível: periódicos.ufsc.br. 
HALITI-PARESI. Plano de Gestão-Haliti-Paresi: Território Indígena Haliti-Paresi. Mato Grosso-Brasil, 2019.

KEZONAZOKERO, Tereza Cristina. O ensino de língua materna na escola da aldeia Rio Verde: preservação e fortalecimento. Barra do Bugres: UNEMAT/FAINDI, 2020. Trabalho de Conclusão de Curso, 2016.

MARTINS, Daniel Valério. A intraculturalidade nas comunidades indígenas da região metropolitana de Fortaleza-CE, Brasil: caminho para o desenvolvimento e sobreculturalidade. Tese (doutorado em) Facultad de Ciencias Sociales de la Universidad de Salamanca, 2015.

MARÍN, José. Educação e Interculturalidade: Conhecimentos, saberes e práticas descoloniais. In: CECHETTI, Elcio e POZZER, Adecir. Educação e Interculturalidade: Conhecimentos, saberes e práticas descoloniais. Blumenau: Edifurb, 2014, p.45.

MARTINS, Daniel Valério. Conceitos de Contatos Culturais e de Intervenção Social que Incidem na Sociedade Latino americana do Século XXI: Intra, Multi, Inter, Trans e Sobreculturalidade. Revista Pluri - Vol. 1, No 1 (2018)

MONTE, Nietta Lindenberg. Política Pública e Educação Escolar indígena no Brasil. In: Conferência Ameríndia: tecendo caminhos da educação escolar. Anais do Congresso de Professores Indígenas do Brasil. Cuiabá-MT: Secretaria de Estado de Educação Escolar Indígena de Mato Grosso, 1997.

NAZKEMAI, Elismara Cristina. A importância da Língua Materna para o povo Haliti Paresi. Aldeia Rio Verde, Tangará da Serra/MT. SEDUC/ Magistério Intercultural Kamahiye, 2018.

PAES, Maria Helena Rodrigues. A questão da língua na escola indígena em aldeias Paresi de Tangará da Serra-MT. Revista Brasileira de Educação. Set/Out/Nov/Dez $2002 N^{\circ}$ 21. Disponível em: https://www.scielo.br/pdf/rbedu/n21/n21a04.

PIVETTA, Darci Luiz. Amazônia Meridional: território deflagrado, educação Pacificadora. 1999. 249 f. Tese (Doutorado em Educação) - Instituto de Educação, Universidade Federal de Mato Grosso, Cuiabá.

SEKI, Lucy. A Linguística Indígena no Brasil. D.E.L.T.A., Vol. 15, N. ${ }^{\circ}$ ESPECIAL, 1999 (257290). Disponível: http://repositorio.unicamp.br.

VIVEIROS DE CASTRO, Eduardo. A inconstância da alma selvagem e ouros ensaios da antropologia. São Paulo: Cosac e Naify, 2002.

\section{ABSTRACT:}

This article presents some reflections related to mother tongue teaching with the Haliti Paresi people. It is the result of some questions raised from the classes at the PostGraduation Stricto Sensu Professional Master in "Teaching in Indigenous Intercultural Context" - UNEMAT, about significant pedagogical practices within the context of the specific, differentiated, intercultural and bilingual school. It addresses the place of the mother tongue in the school and its cultural complexes constituted by stories, memories and its own culture. It localizes the mother tongue as a language of instruction at school, as a linguistic ethnopolitics and as a fundamental factor of ethnic identity.

KEYWORDS: Mother tongue; Haliti-Paresi; Culture.

\section{RESUMEN:}

Este artículo presenta algunas reflexiones relacionadas con la enseñanza de la lengua materna con el pueblo Haliti - Paresi. Es el resultado de algunas cuestiones aportadas desde las clases de la Maestría Profesional de Posgrado Stricto Sensu en "Enseñanza en Contexto Indígena Intercultural" - UNEMAT, sobre prácticas pedagógicas significativas en el contexto de la escuela específica, diferenciada, intercultural y bilingüe. Aborda el lugar de la lengua materna en la escuela y sus complejos culturales constituidos en historias, recuerdos y la propia cultura. Sitúa la lengua materna como lengua de enseñanza en la escuela, como etnopolítica lingüística y como factor fundamental de identidad étnica.

PALABRAS-CLAVES: Lengua materna; Haliti Paresi; Cultura. 